Аликберова А.М. Основные тенденции банковского кредитования как механизма финансирования малого и среднего бизнеса на современном этапе

УДК 336.717 .061

DOI: $10.21779 / 2500-1930-2018-33-2-44-48$

\title{
А.М. Аликберова
}

\section{Основные тенденции банковского кредитования как механизма финансирования малого и среднего бизнеса на современном этапе}

Дагестанский государственный университет; Россия, 367001, 2. Махачкала, ул. М. Гаджиева, 43a; adiyat_86@mail.ru

Обязательным условием успешного функционирования экономики любого государства является наличие развитого сектора малого и среднего бизнеса. В России, как и в большинстве развитых стран, малые и средние предприятия ориентированы на выполнение ряда центральных социально-экономических функций - поддержание конкурентной среды, обеспечение занятости, формирование инновационной экономики и др. В статье изучено состояние малого и среднего бизнеса в современных адаптационных условиях кризисного периода. Рассмотрены общие тенденции развития, среди которых акцентировано внимание на росте просроченной кредитной задолженности, снижении количества выдач кредитов и сжатии кредитного портфеля. Отмечены иные (помимо банковского кредитования) инструменты финансирования предприятий малого и среднего бизнеса. Оценено современное состояние такой превалирующей части малого и среднего бизнеса, как микробизнес. Представлены приоритеты по улучшению доступности финансовых ресурсов для этой сферы предпринимательской деятельности.

Ключевые слова: банковское кредитование, малый бизнес, микробизнес, кредитный портфель, приоритет.

Специфика роли кредита как способа финансирования малого и среднего бизнеса (МСБ) определяется тем, на что товаропроизводители берут кредит. Основной причиной выступает недостаточность собственных средств для обеспечения непрерывности процесса производства (товарооборота). Важно преодолеть затруднения в платежах либо расширить производство. У заемщика появляется возможность за счет дополнительного привлечения кредита увеличить масштабы функционирующего капитала, обеспечивая тем самым не только непрерывность, но и ускорение воспроизводственного процесса.

В настоящее время тенденции в кредитовании малого и среднего бизнеса в России следующие:

- снижение ставок по кредитам малому и среднему бизнесу, соответственно повышение доступности финансирования;

- снижение спроса малого бизнеса на заемные средства;

- рост просроченной кредитной задолженности.

Доля просрочки в сегменте малого и среднего бизнеса в 2016 году побила рекорды. На начало года она составила 14,2 \%. Следует отметить, что в крупных банках, которые в силу более выгодных условий кредитования могут привлекать более качественных заемщиков, кредитный портфель ухудшился незначительно: доля просрочки там возросла на 0,3 п. п., до 13,3 \%. У остальных игроков просрочка увеличилась на 1,1 п. п., достигнув 15,6 \% [1]. 
Аликберова А.М. Основные тенденции банковского кредитования как механизма финансирования малого и среднего бизнеса на современном этапе

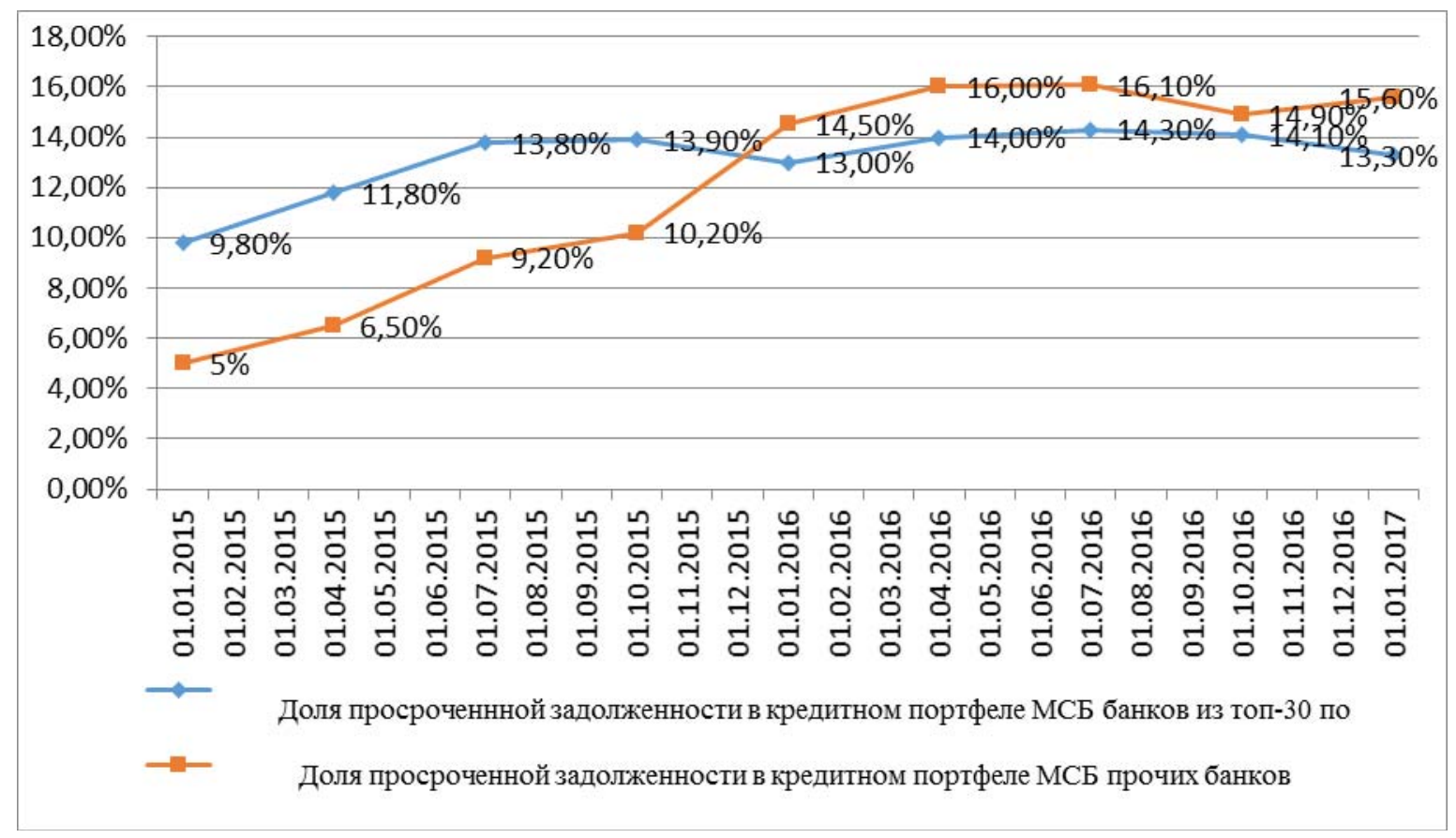

Рис. 1. Доля просроченной задолженности в кредитных портфелях банков в период с 01.01.2015 г. по 01.01.2017 г. ${ }^{1}$

Согласно исследованию, проведенному рейтинговым агентством «Эксперт РА» за 2016 год, рынок кредитования МСБ продемонстрировал негативные тенденции: снижение количества выдач и сокращение кредитного портфеля. Объем выданных кредитов понизился на 3 \%, до 5,3 трлн руб., а размер кредитного портфеля - на 9\%, до 4,5 трлн руб. (что является минимальным значением с 2013 года). Хотя динамика выдач остается отрицательной (снизилась на 3 \%), но все же картина более позитивная, нежели в 2015 году, когда выдачи сократились почти на треть. В 2016 году крупные банки нарастили объем выдач кредитов МСБ на 19 \%. Лидер по величине кредитного портфеля МСБ - Сбербанк. Второе место занимает Россельхозбанк, третье - ВТБ 24 [2].

Бизнесмены учатся работать без заемных средств. Именно те предприниматели, у которых зависимость от заемных средств была минимальной, выжили в кризис.

Среди представителей малого и среднего предпринимательства (МСП) превалирует микробизнес. Согласно данным департамента развития малого и среднего предпринимательства и конкуренции Минэкономразвития, сейчас в стране 5 млн 978 тыс. МСП. Сектор развивается довольно стремительно. Общий прирост с августа 2016 составил более 400 тыс. Около 5 млн - это микробизнес, небольшие компании с численностью сотрудников до 15 человек. Однако большинству из них банковские кредиты недоступны.

Кризис вынудил практически все банки проводить более жесткую политику оценки риска профиля заемщика. Возросла конкуренция за предпринимателей, имеющих недвижимость и иное обеспечение и ведущих прозрачную деятельность. В итоге заемщиками банков становятся более качественные клиенты. Некоторые кредитные органи-

${ }^{1}$ Источник: RAEX (Эксперт РА) по данным Банка России. 
зации, в первую очередь крупные, стали более активно завоевывать рынок и финансировать малый и средний бизнес.

Сегодня малому и среднему бизнесу для получения кредита необходимо иметь достаточный опыт работы - в микробизнесе более 18 месяцев или от 24 месяцев в малом бизнесе. Они реже допускают просрочку платежей. Наличие коммерческой недвижимости является признаком того, что компания проходит кризис без каких-либо существенных проблем. «Белый» бизнес и высокое качество менеджмента, компетентность управляющего персонала, прозрачность в ведении дел показывают, насколько управляемой является компания малого бизнеса, как работает предприниматель, умеет ли он вести бюджет предприятия.

При рассмотрении предпринимателя в качестве заемщика банки в работе с МСБ изучают степень диверсификации партнеров компании. Доля самого крупного покупателя (поставщика) не должна превышать 30 \%, чтобы в ситуации, когда партнеры вдруг подведут, не возникали проблем с получением товара или его реализацией. Важен и определенный период «географической локализации». Анализ периода проживания в регионе ведения бизнеса показал, что компании, руководители которых прожили в этом месте не менее двух-трех лет, оказались менее подвержены влиянию кризиса. В малом бизнесе семейное положение и образование собственника не имеет большого значения для банка. А вот в микробизнесе те клиенты, у которых есть семья, высшее либо среднеспециальное образование, показывают меньшее количество дефолтов и просрочек.

Основные малорисковые заемщики - это производители товаров повседневного спроса, поскольку платежеспособный спрос на эти товары не снижается даже во время кризиса. Самыми рисковыми являются автодилеры, заемщики под строительство, производство товаров категории люкс. По статистике Банка России, в 2016 году просрочка росла именно в этих сферах [3].

Еще одной тенденцией последних лет явилось увеличение финансирования предприятий малого и среднего бизнеса через инструменты, отличные от банковского кредитования, - посредством лизинга и факторинга, т. е. та часть спроса, которую не удалось удовлетворить банкам, переходит в другие сегменты. Но все же банковское кредитование является основным способом финансирования МСБ (86 \% от общего объема финансирования).

Для снижения влияния затянувшегося кризиса на и так уязвимый сектор малого бизнеса правительство России продолжает осуществлять финансовую поддержку начинающим предпринимателям. В частности, с 2017 г. стало возможным получение нескольких форм льготного кредита (рис. 2).

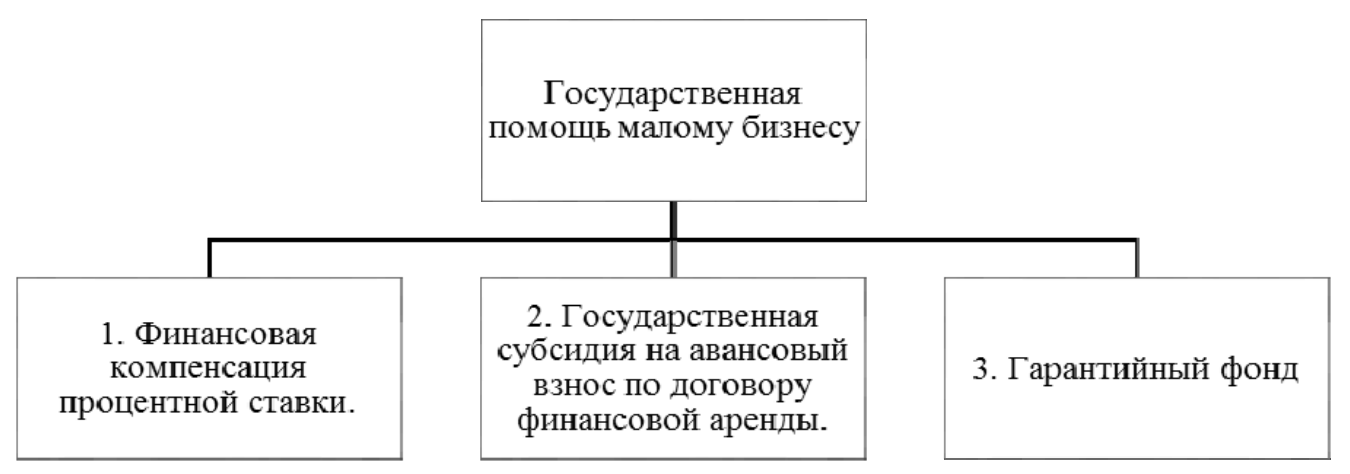

Рис. 2. Виды государственной помощи малому бизнесу 
Финансовая компенсация процентной ставки предполагает возмещение государством части денежных средств, потраченных на модернизацию и переоснащение предприятия. Но подобная компенсация предоставляется только занятым в сфере инновационных разработок, реализацией программ по импортозамещению, предоставлением услуг населению.

Государственная субсидия на авансовый взнос по договору финансовой аренды. Если предприниматель приобретает оборудование или транспорт в лизинг, в рамках такой программы возможно получение существенной скидки на любую технику.

Гарантийный фонд может выступать в качестве поручителя для получения предпринимателем кредита в банке [4].

В рамках Программы поддержки малого и среднего предпринимательства Минэкономразвития России обозначило ряд приоритетов по улучшению доступности финансовых ресурсов для малого и среднего бизнеса, на которых сейчас сосредоточено ведомство:

1. В рамках «Программы 6,5» снижен порог минимального кредита до 5 млн руб. К тому же льготами могли воспользоваться не только юридические лица, но и индивидуальные предприниматели.

2. Развивается Национальная гарантийная система, утверждены единые требования к региональным гарантийным организациям, что должно повысить качество их работы и доступность гарантий соответствующих кредитов для МСП.

3. Принято решение об инициации отбора регионов для формирования в этом году двух региональных лизинговых компаний.

4. В рамках приоритетного проекта Правительства РФ «Малый бизнес и поддержка индивидуальной предпринимательской инициативы» развивается направление, связанное с формированием МФЦ для бизнеса, где субъекты МСП смогут получить весь комплекс услуг - от регистрации бизнеса до услуг финансово-кредитной поддержки.

5. Планируется создание единой образовательной интернет-платформы - он-лайн курсов для субъектов МСП и тех граждан, которые планируют начать свой бизнес, в целях повышения финансовой грамотности предпринимателей в рамках приоритетного проекта. Ожидается, что в скором будущем рынок банковского кредитования МСБ всетаки преодолеет имеющиеся негативные тенденции и продемонстрирует рост [5].

Поддержка малого и среднего бизнеса необходима, и принятие реально действенных мер является жизненно необходимым для их выживания в современных условиях.

\section{Литература}

1. Россия > Финансы, банки. Приватизация, инвестиции $>$ bankir.ru, 10 апреля $2017>$ № 2136889 данные по банковским рейтингам рейтингового агентства «Эксперт PA».

2. Россия $>$ Финансы, банки $>$ bankir.ru, 6 апреля $2017>$ № 2132172 .

3. Россия $>$ Финансы, банки. Приватизация, инвестиции $>$ bankir.ru, 10 апреля $2017>$ № 2136889.

4. Идеи для бизнеса (C KakBiz.ru «Кредиты малому бизнесу от государства в 2017 году» http://kakbiz.ru/kredit/malomu-biznesu-ot-gosudarstva-v-2017-godu.html;

5. Россия > Финансы, банки. Приватизация, инвестиции > economy.gov.ru, 5 aпреля $2017>$ № 2129238.

6. Аликберова А.М. Анализ и оценка рынка кредитования физических лиц: основные тенденции на современном этапе в России и Республике Дагестан // Экономика и предпринимательство. - 2016. - № 11, ч. 3, декабрь. 
7. Щербаков М.А. Современные тенденции банковского кредитования малых и средних предприятий в РФ // Молодой ученый. - 2014. - № 20. - С. 448.

8. Зозулина М.А. Совершенствование механизма банковского кредитования малого и среднего бизнеса // Вестник современной науки. - 2016. - № 5-1 (17) C. 61 .

9. Акаев А.А., Зиядуллаев Н.С., Сарыгулов А.И., Соколов В.Н. Среднесрочный прогноз динамики развития экономики России // Проблемы прогнозирования. - 2016. № 5.

10. Шилов B.A. Проблемы кредитования субъектов малого и среднего предпринимательства в России // Азимут научных исследований: экономика и управление. 2017. - Т. 6, № 1. - С. 213-216.

Поступила в редакиию 14 июня 2017 г.

UDC 336.717.061

DOI: $10.21779 / 2500-1930-2018-33-2-44-48$

\section{Major trends in bank lending as a financing mechanism for small and medium business}

\section{A.M. Alikberova}

Dagestan State University; Russia, 367001, Makhachkala, M. Hajiyev st., 43a; adiyat_86@mail.ru

The obligatory condition of successful functioning of any economy is a developed sector of small and medium business. In Russia, like in other developed countries, small and medium enterprises focused on the implementation of certain economic functions such as maintenance of a competitive environment, employment, the formation of innovative economy etc. The article studies the status of small and medium business in the modern adaptational conditions during the crisis. General tendencies of development, among which the attention is focused on the growth of overdue credit debt, the reduction in the number of issued and compression of a credit portfolio are also discussed. Besides Bank loans, other financing instruments of the enterprises of small and average business are marked. Modern condition of micro business are estimated. The priorities for improving the availability of financial resources for this business area are also presented in the article.

Keywords: bank lending, small business, micro business, loan portfolio, the priority.

Received 14 June, 2017 